\title{
1 Using morphospaces to understand tafoni development
}

3 Rob Inkpen ${ }^{1}$ and Kevin Hall ${ }^{2}$

4

5

1 Corresponding author: Department of Geography, University of Portsmouth, Buckingham Building, Lion Terrace, Portsmouth, Hampshire PO1 3HE United Kingdom Email: robert.Inkpen@port.ac.uk

2 Kevin Hall, Department of Geography, Geoinformatics and Meteorology, University of Pretoria, Pretoria 0002, South Africa

\begin{abstract}
Tafoni research has tended to focus on issues around definition and differences rather than trying to develop general concepts for understanding the nature of tafoni. This paper uses the concepts of fitness landscapes and morphospaces to develop a standardized and dimensionless phase space within which to represent, visualize and analyize a dataset of 800 tafoni collected from Antarctica. Within this phase space it is possible to identify clustering of tafoni forms and to illustrate how tafoni development is constrained by a relational hierarchy of rock structure, processes and geometry or form.
\end{abstract}

Keywords: tafoni, development, fitness landscapes, morphospaces 
27 Tafoni have been the source of debate in geomorphology since the first identification and proposed explanation of this distinctive form (see Groom et al., in Press).

29 Unfortunately, key issues arise again and again in the literature as the supposed 30 'distinctiveness' of this form eludes definition. This elusiveness means that any 31 definitive statement on the characteristics and diagnostic processes of this form are 32 almost impossible to delineate. Specifically, the debate hovers around issues of scale 33 (are 'small' tafoni the same as 'large' tafoni?), development (do small tafoni become 34 large tafoni and is there a distinct developmental sequence to tafoni formation, do they represent self-organization?), and process-form relationships (is there a diagnostic set of processes that cause tafoni to develop and maintain the form?). Research tends to focus on either one or all of these issues. The underlying assumption of form indicating process and changes in form indicating changes in process is at the heart of the measurement and analysis of tafoni.

\subsection{What are tafoni?}

There appears to be a number of terms relating to 'hollows' developed in bedrock, the most common of which (in English) are 'honeycomb' or 'alveolar' weathering and 'tafoni' (e.g. Evelpidou et al., 2010); the whole often being referred to as 'cavernous weathering' (e.g. Turkington and Phillips, 2004; Viles, 2005). The terms 'honeycomb weathering' and 'cavernous weathering' seem to be the catch-all terms for the creation of "small caves" (Evelpidou, et al., 2010) or "caverns" (Turkington and Phillips, 2004) developed by differential weathering in rock. In many of these studies the distinction between form terminology appears to be almost solely related to size 
51 rather than to actual form or process (Groom et al., in Press). This, thus, leaves the question as to whether alveolar weathering is but a precursor of tafoni and/or whether the size distinction is simply a product of the host lithology. According to Evelpidou et al (2010, p. 34), following Penck (1894), "honeycomb weathering formations bigger than $0.5 \mathrm{~m}$ are defined as Tafoni, whereas formations smaller than $0.5 \mathrm{~m}$ are defined as Alveoles"; seemingly the whole defined as 'honeycomb weathering'. Mustoe (1982) provides extensive information regarding nomenclature and some of the confusion resulting from non-standardization of terminology. Cavernous weathering is often used to encompass all the other terms (e.g. French and Guglielmin, (2000) refer to tafoni as an attribute of cavernous weathering) but may also be considered as an entity in its own right (e.g. Dragovich, 1967). Thus, the question arises as to quite what are tafoni and where, if at all, do they fit within the spectrum of other associated terms?

To some extent, many of the background components of this discussion have been covered by Viles (2005) and the reader is directed towards this excellent review. Key within the study of Viles (2005, p. 1471) is the opening statement: "Understanding the initiation, development and significance of landforms remains a central issue in geomorphology." Indeed, the whole issue regarding initiation of these weathering forms remains an enigma (Boxermann, 2005, p.79). However, to the above points must also be added the caveat that 'terminology' (see Hall et al., 2012) requires we all understand the same thing through the use of specific terms; this does not appear to be the case with respect to the terms used here. In part, this may well underpin the observation by Turkington (2004, p.128) that "as more information has been presented their (tafoni and alveoli) possible origins, rather than being clarified, seem 
to have become more confused." Perhaps some of this confusion is related to our use of terms and that perhaps the forms these terms refer to are either a continuum (rather than discrete) or are discrete and not part of a continuum (see Inkpen, 2005, for a discussion on these issues within geomorphology).

Viles (2005) clearly uses the term 'cavernous weathering' to encompass a number of forms (notably tafoni and alveoli - see her Fig. 1) as too do Turkington and Phillips (2004). Here it is argued, much as discussed elsewhere for other processes (see Hall et al., 2012), that the foundational terminology 'cavernous weathering' itself creates confusion - is it (cavernous weathering) the 'process' (as actually implied by the term) or the product (the 'cavern') and if it is the 'cavern' then quite what does this encompass; or is it implying (as does appear to be the case) both process and form? Where, as it would appear here, both process and form are included within the term, then this creates many issues (much as it has in nivation - see Thorn and Hall, 2002) as to the conflating of process and form within one term. Thus, while Viles (2005) makes an excellent case for the advances made regarding 'cavernous weathering', notably the self-organizational attributes of form development, the very real problems of both terminology and process remain. Indeed, Viles (2005, p. 1472) alludes to this very issue where it is stated that the overall outcome "rather than providing a consensus viewpoint or indicating a clearly developing research field, seems to be 'mine are different to yours'." This may, though, be either the very issue or that various workers, simply because the terminology is failing us, do not recognize that they are indeed dealing with comparable forms.

\subsection{Form and process relationships}


103 There clearly is much confusion regarding the nature of the formative weathering (or,

104 rather 'rock decay': see Hall, et al., 2012) - essentially everything from chemical to 105 physical to physico-chemical processes, and almost any combination thereof. This, in

106 itself, need not be a problem as this paper argues. Indeed, the very extent and variety 107 of suggested processes is not necessarily unexpected given that cavernous weathering 108 is azonal in occurrence (Turkington and Phillips, 2004) and found in a variety of

109 lithologies (see Mustoe, 1982, Table 1). Given the variety of identified causative 110 processes, the product appears to be a classic 'convergence of form', as already noted 111 by Turkington and Phillips (2004, p. 666). That being the case, then perhaps the 112 question is one of why do these different processes produce the same end result?

114 In turn this may beg the question, as to whether the processes are any different in their 115 effect on the rock; the effect is to solely disassociate the constituent materials. The 116 nature of that disassociation may well be controlled more by lithology than process. 117 In other words, if 'flaking' (the effect) is the outcome, it can be the product of a 118 variety of causes (wetting-drying, thermal stresses, salt weathering, freeze-thaw, 119 chemical processes, etc) acting alone or in combinations. If that were the case then it 120 may be less important as to what the formative process was and, in turn, suggests rock 121 properties may play the key role (see Hall et al., 2012). It may also be, however, that 122 it is the relations between the form and process and the factors that control these 123 relations, rather than the dominance or otherwise of any particular component, that is 124 the essential aspect to understanding any generalized conceptualisation of tafoni 125 evolution. 
127 Burridge and Inkpen (2015) highlight this in the mathematical model of tafoni

128 development. In this paper rock properties provide the context within which process

129 operate to produce the tafoni form. One might argue that, given convergence of form

130 resulting from a multitude of identified processes, then maybe the focus of research

131 should be on underlying factors such as rock properties that can constraint

132 development or, in a more subtle conceptual framework, the relations between factors

133 that may be canalizing development.

135 This paper suggests that this seemingly unsatisfactory state of affairs may help in

136 developing a novel conceptual framework within which to interpret tafoni. This paper

137 suggests that viewing tafoni within the conceptual framework of fitness landscapes

138 and morphospaces permits 'fuzziness' in definitions within the context of the factors

139 that constrain development and which define the parameter phase spaces for tafoni

140 development. In order to advance this argument we first outline the nature of fitness

141 landscapes and morphospaces. Secondly, we identify the three key factors and their

142 parameter phase spaces that constrain tafoni as derived from the existing literature.

143 We highlight the importance of a relational view of these factors for defining the

144 canalizing outcome in phase space. By canalizing we mean that the parameter spaces

145 confine and guide the development of forms along specific pathways. As individual

146 tafoni become increasingly embedded within these developmental pathways, the

147 constraints imposed by these parameter spaces become increasingly difficult to

148 overcome. Lastly, using this conceptual framework we illustrate how it might be used

149 to interpret simple dimensional measurement of tafoni derived from Dronning Maud

150 Land in the Antarctic. From this analysis we are able to show that tafoni inhabit a 
151 restricted area of the phase space and that the detailed analysis of dimensions within

152 this zone may not yield any additional information about process and form

153 relationships. If appropriate then this conceptual framework suggests which aspects of

154 form-process relationships should be the focus of further research into tafoni

155 development.

156

157 2. Fitness Landscapes and Morphospaces

159 Within the biological literature, as noted by McGhee (2007), the concept of 'adaptive

160 landscapes' originates with Wright (1932) who used the concept to visualize the

161 fitness of genes, although he coined the term 'fitness landscape' for his visualization

162 (Figure 1). The adaptive landscape represents all the possible combinations of genes

163 that an organism might produce. From these possible combinations, those that

164 actually existed could be identified and plotted. The fittest of the existing

165 combinations could be thought of as peaks rising from the relatively unfit surface. In

166 Figure 1, for example, there are two possible 'fit' peaks and Wright proposed that

167 evolution by natural selection would force gene combinations to climb the nearest

168 peak, always moving gene combination towards fitter variants. Movement is also

169 informed by local conditions, so even if a nearby peak is lower than the lowest peak

170 globally, variants will move towards that nearest, lower peak. The topography of a

171 fitness landscape provides a roadmap of possible evolutionary pathways. Adaptive

172 landscapes have also been defined in hyperdimensions by Kaufmann (1995);

173 Gaverilets and Gravener (1997) and Gavrilets (2003); and with the latter suggesting

174 that the complex and multiple nature of parameters affecting adaption result in a

175 relatively flat but multidimensional landscape covered with holes. The holes represent 
locations where planes of fitness intersect and so are regions or clusters of hyperspace

177 where fit gene combinations can occur. In the above author's landscape, evolution can

178 be 'smooth' within the clusters but 'jumpy' as gene combinations move from one

179 cluster to another through 'extradimensional bypasses' (Gavrilets (1997, p.311).

180 Within geomorphology Phillips (2009) outlined a similar vision of landscape

181 evolution with his concept of Landscape Evolution Space (LES), an n-dimensional

182 space or hypervolume representing the resources, energy, and the parameters

183 available for landscape development. Conceptually, any landscape should be capable

184 of being located within this hypervolume and its trajectory or development mapped

185 out in the same space. Inkpen and Petley (2007) offer something similar in their

186 analysis of landform development.

187

188 Theoretical morphospaces are not the same as adaptive landscapes but are related to 189 them (McGhee, 2007). Developed by Raup (1966, 1967), a morphospace can be 190 described as a hyperspace of geometries, with axes representing different 191 morphological traits, that represent all the forms possible if these traits are 192 systematically altered. Within a morphospace the axes represent dimensions and 193 form; the resulting surface is a representation of how frequently that form appears.

194 The morphospace provides an indication of the forms that occur in reality, and 195 importantly, those that do not. The two types of space can be linked if the distribution 196 of forms in the morphospace have adaptive significance. Raup (1966), for example, 197 studied the form of ammonoids and identified that there was a distinct pattern to this 198 distribution in morphospace. Chamberlain $(1976,1981)$ through experimental work 199 on models, found that the two regions of morphospace created by ammonoid forms 200 were those where swimming efficiency was maximised. Form was linked to 
201 adaptation. Regions of morphopsace do not necessarily match to peaks that optimise 202 a specific function, but rather, as in the research into plant morphospaces by Niklas 203 (1997, 2004), the peaks represent geometries that minimize several functional 204 problems. This highlights that fitness is always a concept that needs to be thought of 205 in multidimensional terms.

207 Combining the two spaces, McGhee (2007) develops an argument that they can be 208 used to explore the constraints that exist upon development. Fig. 2 illustrates the 209 concept that development is constrained by a series of factors; geometric, functional, 210 phylogenetic and developmental in the case of organisms. McGhee defined the 211 geometric and functional constraints as extrinsic, being imposed by the laws of 212 physics and chemistry, whilst phylogenetic and developmental constraints were 213 intrinsic, imposed by the biology of specific organisms. Assuming a form can be 214 defined by a set of measurements then the total possible set of forms will be defined 215 by points in a hyperspace as in Fig. 2. Within this set of possible forms will be a 216 subset of forms that represent all geometrically possible forms (GPF in Fig. 2). Co217 ordinates outside of this region of hyperspace represent geometrically impossible 218 forms. McGhee defines the boundary between these regions of hyperspace as the 219 'geometric constraint boundary'. Nested within the GPF are two other regions, 220 functionally possible forms (FPF) and functionally impossible forms (FIP). The result 221 is a clearly defined subset of hyperspace that demarcates the region of possible forms 222 given the nested series of constraints. Importantly, the extrinsic constraints remain 223 constant and define rigid boundary conditions, whilst the intrinsic constraints vary 224 with taxon and so are more flexible in the boundaries they prescribe. Recent work on 225 the simulation of vegetated aeolian landscapes (Baas, 2007; Baas and Nield, 2007, 
2010; Nield and Baas, 2008) provide illustrations of the clustering of forms in a

227 simulated parameter space.

229 Brierley (2010), building upon Brierley and Fryirs (2005), identifies a structuring of 230 explanations concerning landscape development in a similar manner: identifying 231 geologic, climatic and anthropogenic memory. Brierley views these three types of memory as imposing differing limits upon landscape development. Geologic memory 233 imposes boundary conditions within which contemporary landscape-forming 234 processes continue to operate, whilst climatic memory controls the nature and 235 effectiveness of geomorphic processes. Anthropogenic memory alters the fluxes of 236 sediment and flows in the landscape. Brierley (2010) is at pains to point out that these 237 factors operate collectively and variably across different time frames despite the 238 temptation to view them as hierarchical. This suggests that explanation in 239 geomorphology is structured around sets of parameters that continually constrain the 240 possible forms and the potential pathways of their development.

242 There may be a basis for seeing a conceptual analogy between morphospaces and 243 fitness spaces and the concept of strange attractors (Phillips, 1999, 2003). Both sets of 244 concepts discuss mapping system properties in a phase space within which certain 245 portion of space are more likely to be populated than others. Within Phillips' 246 discussion, strange attractors are areas of phase space to which evolutionary 247 trajectories are drawn. In the language of morphospaces this means that the zone of 248 the attractor will define a region of particular form characteristics. Within this region 249 there will be a highly proportion or percentage of measured individuals. The attractor 250 need not represent an evolutionary basin but rather the range of forms that can be 
251 taken given variations in constraining properties. The most frequent forms represent

252 the most common outcome but other forms nearby could represent the manifestation 253 of slightly different relations between constraining properties and yet still define a 254 basin of attraction.

256 Application of both concepts to geomorphology does, however, face key problems 257 that mirror those found within biology. Fitness spaces need to be defined in relation to 258 some concept of fitness that then needs to be translated into empirical, measurable 259 terms for defining the extent of morphospace. Identifying 'fitness' implies having a 260 clear concept of the expected trajectory of a form and a clear understanding of the 261 basis for this trajectory. Similarly, the plotting of individuals within a morphospace requires the identification and quantification of important characteristics of form. Our

263 traditional ways of thinking about tafoni from affect what forms we identify in the 264 field and what we deem important to measure. Likewise, technical constraints such as 265 the type of equipment available, its measurement resolution and the ability to 266 consistently measure a highly variable natural phenomenon will all impact upon the nature and quality of data available to characterise forms.

\section{The Spaces of Tafoni}

271 Combining fitness landscapes and morphospaces it is possible to analyse the 272 parameters that define the morphospaces of tafoni and then the manner in which these 273 forms change as tafoni form clusters and developmental sequences. The 274 morphospaces that combine to constrain tafoni formation, development and form are 275 structural, process-based and geometric. These three morphospaces are related to each 
as in Fig. 3, in a nested hierarchy with each additional space constraining the potential

277 location of tafoni in the morphospaces. It is important to bear in mind that the figure

278 is a representation of multidimensional spaces of rock structure, process and geometry 279 and their relations in two-dimensions; it is a visual aid to interpretation. Fig. 3 280 illustrates that tafoni development is constrained by rock structure but rock structure 281 itself is not sufficient to determine whether tafoni develop. Rock structure instead 282 defines a section of morphospace within which tafoni could develop. Potential tafoni 283 development in this morphospace is further constrained by other factors as discussed 284 below. Collectively these form the hierarchy of constraining factors as illustrated in 285 the figure. Burridge and Inkpen (2015) outline a similar hierarchical structure to 286 modelling tafoni development. Rock properties provide the context within which 287 processes operate to produce a geometry of form which then feedbacks to process and 288 affects rock properties.

290 Structural or rock property constraints refer to the various parameters associated with 291 rock properties that have been identified in the past as being associated with tafoni 292 formation. These include inherent weaknesses in the rock, fractures, cracks, as well as 293 porosity, permeability and rock composition. It is within this structurally defined 294 constrained morphospace that processes of weathering and erosion operate and, 295 importantly, interact with each other and with the structural parameters. Structural 296 morphospace may constrain the potential for tafoni to develop but it is not sufficient 297 on its own to determine whether tafoni will develop.

299 Tafoni are inherently about the relations between parameter spaces. For process300 defined morphospace it is not the specific processes that are important but rather the 
nature of the relations between these processes and between these processes and structural parameters. Processes capable of inducing stresses in the near-surface of the rock, which then result in the differentiation of the surface and subsurface properties, are how process-defined morphospace and structural morphospace interact. This means that a range of processes can be vital for tafoni formation. It is not a specific

306 process that causes tafoni to develop but rather it is the result of process relations, in 307 conjunction with rock properties, that produces surface and subsurface differentiation 308 and near-surface stress. Further, this is not a static relationship. Processes and 309 structure interact and in so doing change the nature of that interaction. This means 310 that the morphospaces evolve as well. The structural constraints are initially set very 311 broadly. Adding the process relations produces a refinement of which parts of the 312 spaces are able to develop tafoni. The ongoing interaction between the two further 313 refines this space of potential development and can even expand the spaces of 314 potential as structural properties are altered at the micro-level to become increasingly 315 conducive to tafoni development.

317 An outcome of the complicated relationship between structure and process is the 318 development of a distinct geometry to the resultant form. This is the geometric space, 319 a further constraining morphospace. Once the characteristic tafoni form begins to 320 develop there is an interaction with the processes causing surface and subsurface 321 differentiation. The nature of this relationship determines the development of the 322 geometry of the form that in turn affects the dynamics of the structural and process 323 relationships. This further constrains the spaces of tafoni development as well as 324 altering the nature of structural and process spaces to redefine the locations of 
potential tafoni development. Combined these three spaces produce a nested hierarchy of potential spaces for tafoni.

328 Conceptually, the interaction of the three spaces creates broad regions or clusters 329 where tafoni could develop. These clusters need not be contiguous. This means that 330 tafoni of different sizes and shapes are all tafoni formed through the relations between 331 these three parameter spaces, just formed at different intersections of these parameter 332 spaces. This also means that there is not necessarily a developmental sequence from 333 small through middle-sized to large tafoni. The size distribution need not represent a 334 developmental sequence but rather a different combination of relations.

336 This means that it could be that different studies have revealed different clusters of 337 tafoni and so different locations of potentiality in the relations between these 338 parameter spaces. Once tafoni are initiated then they will develop into forms 339 constrained by the morphospace. Although the potential forms may be varied there 340 will be limits, boundaries, to these forms. It may be that small tafoni will always 341 remain small as their development is confined within a specific region of tafoni 342 morphospace. Small tafoni can not suddenly jump across morphospace and explore 343 the region inhabited by large tafoni. Likewise large tafoni may initially develop 344 rapidly as the relations between structure, process and geometry permit the rapid 345 exploration of potentiality in that region of morphospace. Once trapped along a 346 particular developmental pathway, however, it may be that the rate of growth slows as 347 the limits to that particular pathway are reached. Wright described this process as 348 channelization of forms, as outlined in section 2. A deep cavern, for example, may be 349 too deep for differentiation between surfaces to occur as weathering products can not 
350 be removed to permit further erosion. Conceptually this is limiting the space of 351 potential development for a tafoni as it develops and alters the relations between the 352 morphospaces of the three parameters.

\section{Illustration of Interpretation of Tafoni Space}

355 Tafoni were measured in Dronning Maud Land, Antarctica in the Austral summers of 356 2008/08 and 2010/11. Tafoni were measured on nunataks on the Ahlmannryggen 357 (Ahlmann Ridge), specifically on nunataks, Vesleskarvet (Northern Buttress; $71^{\circ} 40^{\prime}$ S, $\left.358 \quad 2^{\circ} 51^{\prime} \mathrm{W}\right)$, Lorenzenpiggen $\left(71^{\circ} 45^{\prime} \mathrm{S}, 2^{\circ} 50^{\prime} \mathrm{W}\right)$, Grunehogna $\left(72^{\circ} 02^{\prime} \mathrm{S}, 2 \mathrm{o} 48^{\prime} \mathrm{W}\right)$, 359 Flarjuven Bluff $\left(72^{\circ} 01^{\prime} \mathrm{S}, 3^{\circ} 24^{\prime} \mathrm{W}\right)$ and Robertskollen $\left(71^{\circ} 27^{\prime} \mathrm{S}, 3^{\circ} 15^{\prime} \mathrm{W}\right)$. The rock in 360 the area is Precambrian in origin and the exposures measured were of the 361 Borgmassivet Intrusives comprising doleritic and dioritic sills. Measurements were 362 made on 40 rock faces, starting sampling at the central point of each rock face and 363 then measuring the dimensions of the tafoni away from the centre of the rock face

364 until 10 tafoni had been measured. Dimensions were measured using a set of callipers 365 and undertaken by the same observer to ensure consistency in the field definition of 366 length, width and depth.

368 The tafoni dataset was converted to dimensionless values using width/length and 369 depth/width ratios and a phase space constructed using these dimensionless 370 parameters as axes. The data were converted to dimensionless values to analysis form 371 changes within the phase space rather than focusing on changes in the size of the 372 tafoni. If the form of the tafoni, i.e. the relative dimensions of length, width and depth, 373 did not change as it grew then more and more tafoni would occupy the same area of 374 phase space. Fig. 4 illustrates the distribution of tafoni in this dimensionless phase 
space with cells along the $\mathrm{x}$ and $\mathrm{y}$ axes of 0.2 units. The contours represent the percentage of the tafoni in the dataset of 800 individuals occupying specific areas of the phase space. Although these dimensionless ratios have been used in tafoni research before they have not been used to map the distribution of tafoni in such as phase space. Fig. 4 shows a single peak to the distribution of tafoni at around 0.6-0.8 units of both the width/length and depth/width axes with a relatively smooth and continuous decrease around this peak in the occurrence of tafoni. There seems to be a tail in the distribution in the direction of higher depth/width ratios suggesting that there are a number of tafoni becoming deepening whilst retaining a form consistent with those tafoni in the peak area. The single peak and the relatively even spread of tafoni away from it might imply the peak represents the end point of an evolutionary or developmental sequence for tafoni. The relative frequencies of tafoni in the phase space would, if this were the case, represent the stages in tafoni evolution with the peak being the most frequent and final stage. Tafoni not in the peak might represent individual tafoni that had not yet developed to their final form or tafoni where the relations between rock structure, process and geometry in this environment were not as fully expressed as in the peak.

The contiguous nature and relatively plateau-like nature of the frequency surface in phase space may, however, suggest that the differences between a tafoni at the peak and one in the sub-peak areas may not mean that different processes are at work or that tafoni are at different stages of development. Rather the different zones represent the differing expression of the same set of rock structure, process and geometry relationships. This means that differences in form can not necessarily be interpreted to mean differences in how the tafoni form, only differences in the relative importance 
400 of each factor. This means that the exact position of an individual tafoni in the phase

401 space need not reflect major changes in constraining factors nor in the relations that

402 produce its final form. A cloud of individual tafoni positions may reflect the same

403 relations just expressed slightly and insignificantly differently.

404

405 Analysis of variance suggests that there is no statistically significant difference

406 between the tafoni in the three cells forming the plateau region in terms of length and

407 width but depth increases significantly between these cells (analysis of variance with

408 an F value of 0.8 for length and 0.69 for width, both statistically not significant and an

409 F value of 9.43 for depth statistically significant at $\alpha=0.01$ ). Moving away from the

410 plateau there are statistically significant differences in length, width and depth as

411 might be expected as the ratios change. The nature of the change is consistent in that

412 length, width and depth increase alone in specific areas of the morphospace so

413 significant changes result from the increase in size of a single dimension rather than

414 decreases in size.

416 Fig. 5 illustrates the variation in statistically significant increases in length, width and 417 depth of tafoni in the morphospace. Tafoni in this dataset have a limited depth of 10-

$41815 \mathrm{~cm}$ whatever the form of the tafoni. This implies that there is a vertical limit to

419 tafoni development, suggesting that the relations between the three key factors only

420 operate within a $10-1 \mathrm{~cm}$ depth from the rock surface. This depth-limit to relationships

421 between factors was also found in the mathematical modelling of tafoni in Burridge

422 and Inkpen (2015) and may suggest that tafoni development is a depth-limited

423 process. The bottom left of the phase space is dominated by tafoni with high average

424 lengths compared to tafoni in every other part of the phase space. This suggests that 
tafoni in this section of the phase space are elongated and may represent either controls on shape trough rock structure or the coalescence of tafoni lengthwise. The right-hand side of the phase space at mid D/W ratios has high average widths for tafoni compared to tafoni across the rest of the phase space. This suggests that tafoni move to this portion of phase space through widening rather than overall growth in

430 dimensions, as the average tafoni length is not significantly different from the tafoni 431 in the rest of the phase space.

433 The morphospace produced illustrates the constraining nature of the three parameters.

434 Rock properties form the common context within which the tafoni develop and the 435 single peak in morphospace implies that this constraint usually produces a single, 436 characteristic set of forms. Process is constrained to the process specific to this 437 environment and the geometry of form seems to be highly constrained to a limited set 438 of ratios between the dimensions measured. The morphospace produced represents 439 the range of tafoni form produced within this rock type, in this weathering 440 environment and provides a template against which to map other tafoni from other 441 environments as well as tafoni of lager and smaller dimensions. If the tafoni from 442 other environments map into a similar zone then this implies that the relations 443 between rock properties, process and geometry are consistent across environments 444 and so forms converge into a specific region of morphospace. If, however, tafoni 445 from other environments map to a different region of morphospace then this implies 446 that there are significant differences in how the relationships between the factors are 447 expressed in different environments. In this case there is a basis for claiming some 448 tafoni are different from others and to question the common terminology to describe 449 them. 


\section{Conclusion}

454 Expressing the data within a standardized and dimensionless phase space allows the 455 researcher to visualize the forms within a common setting. This can help the 456 researcher to identify patches of the phase space where forms cluster, and to provide a 457 definition of the characteristics that define these clusters in terms of dimensional 458 relationships. Comparing the location of clusters between studies could help to 459 identify if there is a common pattern to clustering within this phase space or if the 460 location and nature of the clusters vary with each study. This will help to distinguish 461 and define tafoni that present common patterns in form relationships and tafoni whose 462 form relationships express their site-specific nature. Making this distinction will help 463 researchers define forms which could be classified as tafoni in any environment as 464 opposed to forms that exhibit tafoni-like tendencies but which cluster in a different 465 part of the phase space. 'Mine is different from yours' becomes less of a problem as 466 here is a way of visualizing if and by how much mine is different from yours and if 467 the difference might be significant.

469 The role of form and process, as well as the relative importance of other factors, can 470 be analysed using the hierarchical model of morphospaces presented above. The 471 central importance of rock structure defines the limits to the range of forms possible 472 and so could be viewed as the overarching control on the potential for tafoni to 473 develop. Whether tafoni develop or not is not solely determined by rock structure 474 however. The relationships between rock structure and weathering and erosion are 
475

\section{References} tested.

vital for determining if tafoni develop and which areas of the phase space the forms inhabit. Producing stress in the near-surface is the key outcome that affects tafoni production and the evolving relationships between processes and form, tightly constrained by structure, establishes the developmental and geometric relationships that are expressed by the forms measured. This could mean that different processes produce different clusters in phase space and so process identification may be aided by mapping these clusters. It may be, however, that the clusters are so broad, as in this example, that the differentiation between processes is not feasible. This could imply that the range of forms produced within the constraints of the morphospace defined by rock structure is potentially large as subtle variations in process-form relationships can be expressed by a wide range of dimensional outcomes. With only one set of data it is difficult to assess if this is a general characteristic of tafoni but setting the discussion within this common framework would enable these key hypotheses to be

\section{Acknowledgements}

The authors would like to thank Ian Meiklejohn, Christel Hansen, Michael Loubser and Werner Nel for the tafoni datasets that were from the 'Landscape Processes in Antarctic ecosystems' project funded by the South African NRF. The authors would also like to thank two anonymous reviewers for their constructive comments. 
500 Baas, A.C.W., 2007. Complex systems in Aeolian geomorphology. Geomorphology, $50191,311-331$.

Baas, A.C.W., Nield, J.M., 2007. Modelling vegetated dune landscapes. Geophysical

504 Research Letters 34, p.06405.

505

506 Baas, A.C.W., Nield, J.M., 2010. Ecogeomorphic state variables and phase-space

507 construction for quantifying the evolution of vegetated Aeolian landscapes. Earth

508 Surface Processes and Landforms 35, 717-731.

509

510 Boxerman, J.Z., 2005. The evolutionary cycle of the tafoni weathering pattern on

511 sandstone at Bean Hollow Beach, Northern California. Geological Society of America

512 Abstracts with Programs 37(4), 79.

513

514 Brierley, G.J., 2010. Landscape memory: the imprint of the past on contemporary

515 landscape forms and processes. Area 42, 76-85.

516

517 Brierley, G.J., Fryirs, K.A., 2005 Geomorphology and river management: applications 518 of the river styles framework. Blackwell, Oxford.

520 Burridge, J., Inkpen, R., 2015. Formation and arrangement of pits by a corrosive gas.

521 Physical Review E 91, 022403.

523 Chamberlain, J.A., 1976. Flow patterns and drag coefficient of cephalopod shells.

524 Palaeontology 19, 539-563. 
526 Chamberlain, J.A., 1981 Hydromechnical design of fossil cephalopods in M.R. House

527 and J.R. Senior (eds,) The Ammonoidea. Systematics Association, London. pp.289528336.

530 Dragovich, D., 1967. Flaking, a weathering process operating on cavernous rock 531 surfaces. Geological Society of America Bulletin 78, 801-804.

533 Evelpidou, N, Leonidopoulou, D. and Vassilopoulos, A., 2010. Tafoni and alveole 534 formation. An example from Naxos and Tinos Islands. In Evelipou, N., de Figueiredo, 535 T., Mauro, F., Tecim, v. and Vassilopoulos, A. (eds,) Natural heritage from East to 536 West. Case studies from 6 EU Countries. Springer. 35-42.

538 French, H.M., Guglielmin, M., 2000. Cryogenic weathering of granite northern

539 Victoria land, Antarctica. Permafrost and Periglacial Processes 11, 305-314.

541 Gavrilets, S., 1997. Evolution and speciation on holey landscapes. Trends in Ecology 542 and Evolution 12, 307-12.

544 Gavrilets, S., 2003. Evolution and speciation in a hyperspace: The roles of neutrality, 545 selection, mutation and random drift. In, Crutchfield, J.P. and Schuster P. (eds,)

546 Evolutionary dynamics. Oxford University Press, Oxford.

548 Gavrilets, S., Gravner, J., 1997. Percolation on the fitness hypercube and the 549 evolution of reproductive isolation. Journal of Theoretical Biology 184, 51-64. 
550 Glossary of Geology. 2005. Fifth edition. Neuendorf, K.K.E. and Mhel, Jr. ,J.P. (eds)

551 Guglielmin, M., Cannone, N., Strini, A., Lewkowicz, A., 2005. Biotic and abiotic

552 processes on granite weathering landforms in a cryotic environment, Northern

553 Victoria Land, Antarctica. Permafrost and Periglacial Processes 16, 69-85.

554 Groom, K., Allen, C.D., Mol, L., Paradise, T.R., Hall, K., In Press. Defining tafoni:

555 Re-examining terminological ambiguity for cavernuous rock decay. Progress in

556 Physical Geography.

557 Hall, K., Thorn, C., Sumner, P., 2012. On the persistence of 'weathering'.

558 Geomorphology 149, 1-10.

559 Inkpen, R., 2005. Science, philosophy and physical geography. Routledge, London.

560

561 Inkpen, R., Petley, D., 2001. Fitness spaces and their potential for visualizing change

562 in the physical landscape. Area 33, 242-251.

563

564 Kauffman, S., 1993. Origins of Order: Self-organization and Selection in Evolution.

565 Oxford University Press, New York.

566 Kaufmann, S., 1995 At home in the universe. Penguin, London.

567

568 Kejonen, A., Kielosto, S., Lahti, S.I., 1988. Cavernous weathering forms in Finland.

569 Geografiska Annaler 70A (4), 315-321.

570 
571 McGhee, G.R., 2007. The geometry of evolution: Adaptive landscapes and theoretical 572 morphospaces. Cambridge University Press, Cambridge.

573

574 Mustoe, G.E., 1982. The origin of honeycomb weathering. Geological Society of 575 America Bulletin 93, 108-115.

576

577 Neild, J.M., Baas, A.C.W., 2008. The influence of different environmental and

578 climatic conditions on vegetated Aeolian dune landscape development and response.

579 Global and Planetary Change 64, 76-92.

580

581 Niklas, K.J., 1997. The evolutionary biology of plants. University of Chicago Press, 582 Chicago.

584 Niklas, K.J., 2004. Computer models of early land plant evolution. Annual Review of 585 Earth and Planetary Sciences 32, 47-66.

586

587 Ollier, C.D., Bourman, R.P., 2002. Flared Slopes, Footslopes, and the Retreat of 588 Overhanging Slopes: Examples of Convergent Landform Development. Physical 589 Geography 23, 321-334.

590

591 Owen, A.M., Atersrat, W.J., Mylroie, J.E., Mylroie, J.R., 2005. A morphological 592 comparison of tafoni vs. flank margin caves, San Salvador Island, Bahamas.

593 Geological Society of America Abstracts with Programs 38 (7) 62. 594

595 Penck, A. 1894. Morphologie der Erdoberfläche. Stuttgart, Engelhorns, Vol I, 214 
597 Phillips, J.D., 1999. Earth surface systems: complexity, order and scale. Blackwell, 598 Oxford.

599

600 Phillips, J.D., 2003. Sources of nonlinearity and complexity in geomorphic systems.

601 Progress in Physical Geography 27, 1-23.

602

603 Phillips, J.D., 2009. Landscape evolution space and the relative importance of

604 geomorphic processes and controls. Geomorphology 109, 79-85.

605

606 Raup, D.M., 1966. Geometric analysis of shell coiling: General problems. Journal of 607 Palaeontology 40, 1178-1190.

608

609 Raup, D.M., 1967. Geometric analysis of shell coiling: Coiling in Ammonoids.

610 Journal of Palaeontology 41, 43-65.

611

612 Thorn, C.E., Hall, K., 2002. Nivation and cryoplanation: the case for scrutiny and

613 integration. Progress in Physical Geography 26, 533-550.

614

615 Turkington, A., 2004. Cavernous weathering. In: Goudie, A.S. (ed.), Encyclopaedia of

616 Geomorphology. Routledge, New York. 128-130.

617

618 Turkington, A., Phillips, J.D., 2004. Cavernous weathering, dynamical instability and 619 self-organization. Earth Surface Process and Landforms 29, 665-675.

620 
621 Viles, H.A., 2005. Can stone decay be chaotic? In Stone Decay in the Architectural

622 Environment, Turkington AV (ed). Geological Society of America Special Paper 390,

$62311-16$.

624

625 Walker, L.N., Mylroie, J.E., Walker, A.D., Mylroie, J.R., 2008. The Caves of Abaco

626 Island, Bahamas: keys to geologic timelines. Journal of Cave and Karst Studies 70,

$627 \quad 108-119$.

628

629 Wright, S., 1932. The role of mutation, inbreeding, crossbreeding, and selection in

630 evolution Proceedings of the Sixth International Congress on Genetics 1, 355-65.

631

632

633

634 Figure Captions

635

636

637

638

639

640

641

642

643

644

645

646

647

648

649

650

651

652
Figure 1 Illustration of fitness landscape (Modified from Wright, 1932)

Figure 2 Illustration of concept of development within a morphospace constrained by series of factors (Modified from McGhee, 2007)

Figure 3 Relationship between structural, process-based and geometric factors in morphospaces as a nested hierarchy

Figure 4 Morphospace of percentage frequency of tafoni occurrence for specific width/length and depth/width ratios

Figure 5 Illustration of changes in tafoni length, width and depth across morphospace 


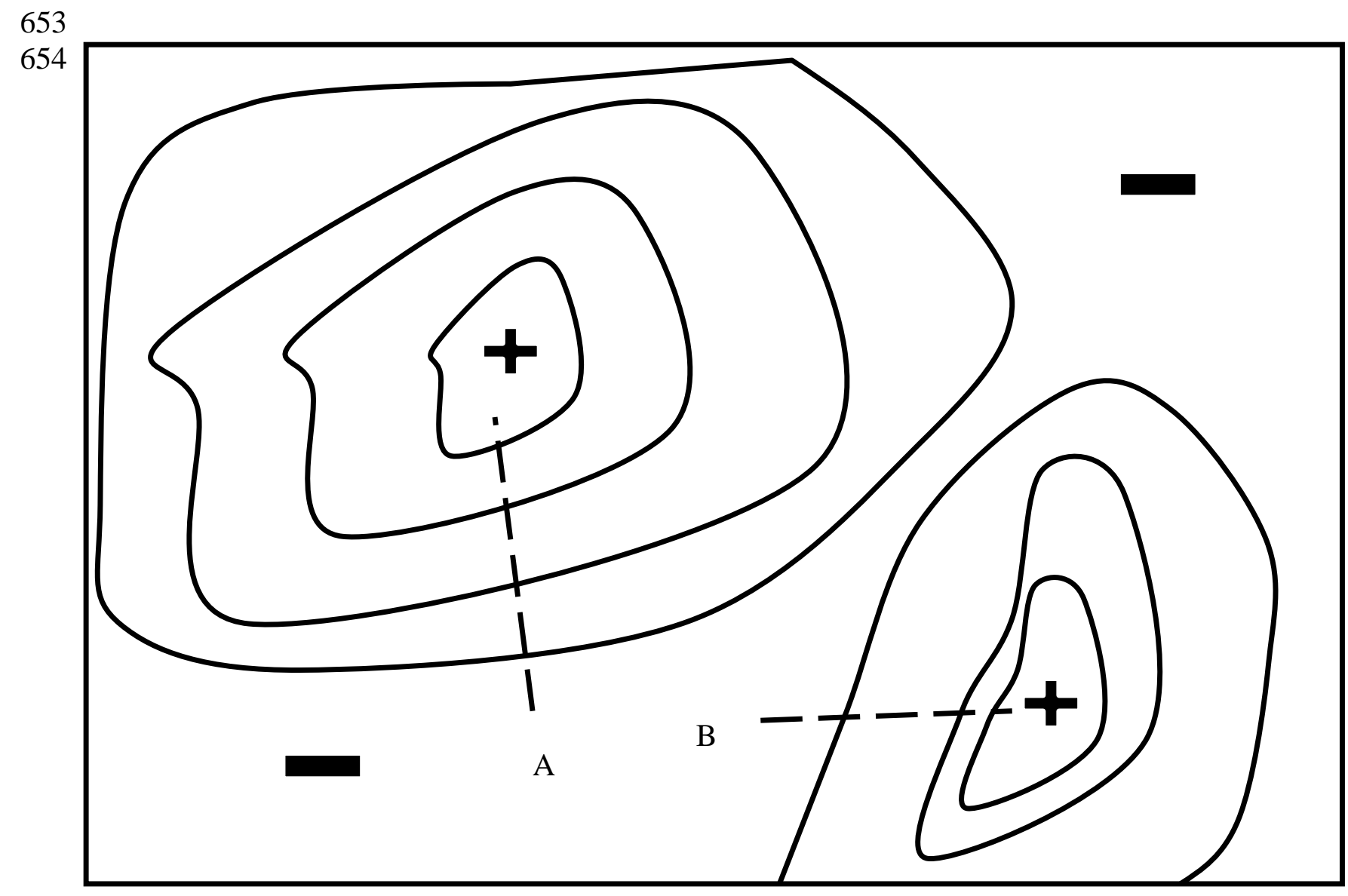


655

656

Total Hyperspace of Form Dimensions (axes represent different hyperdimensions)

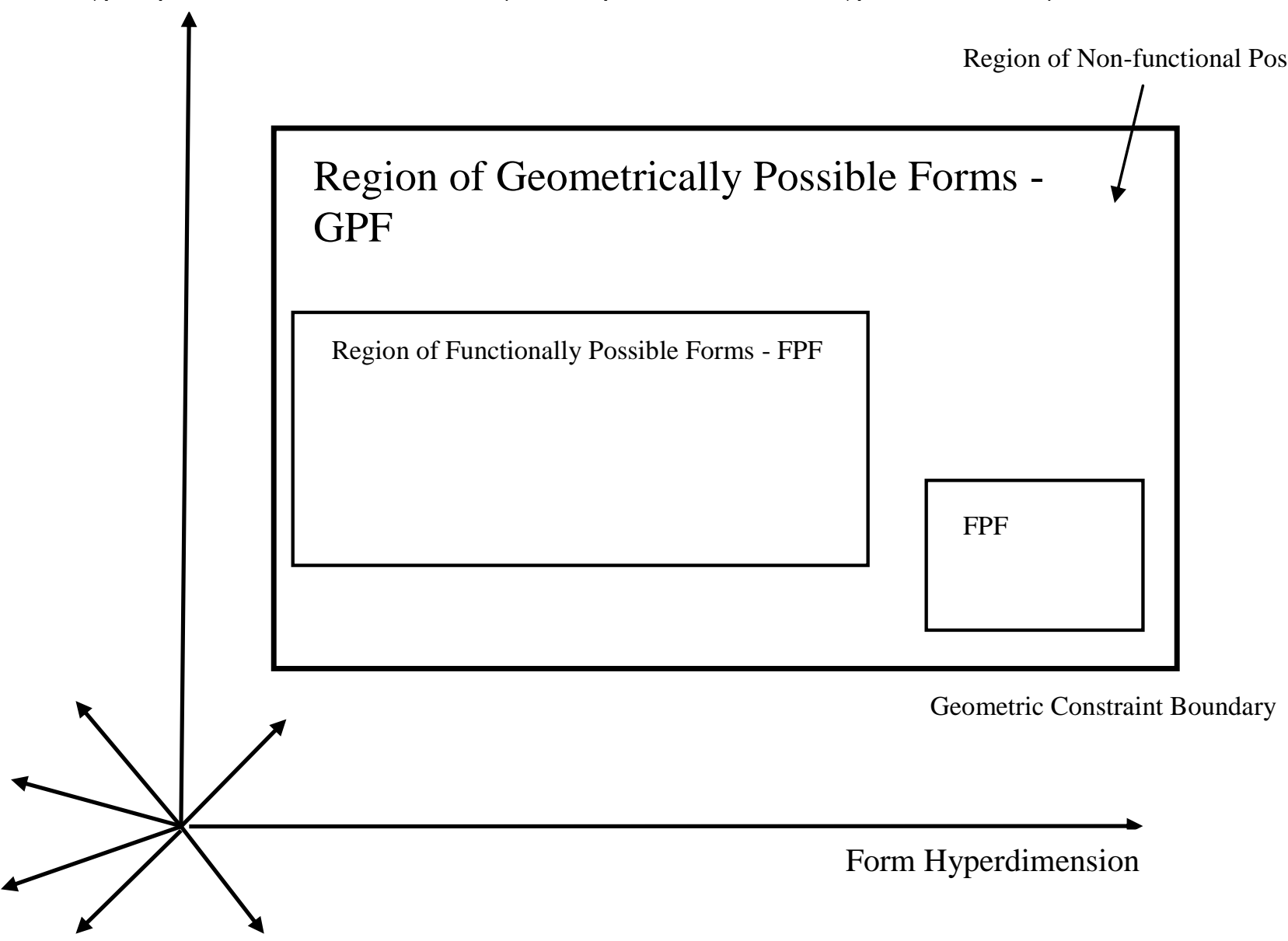




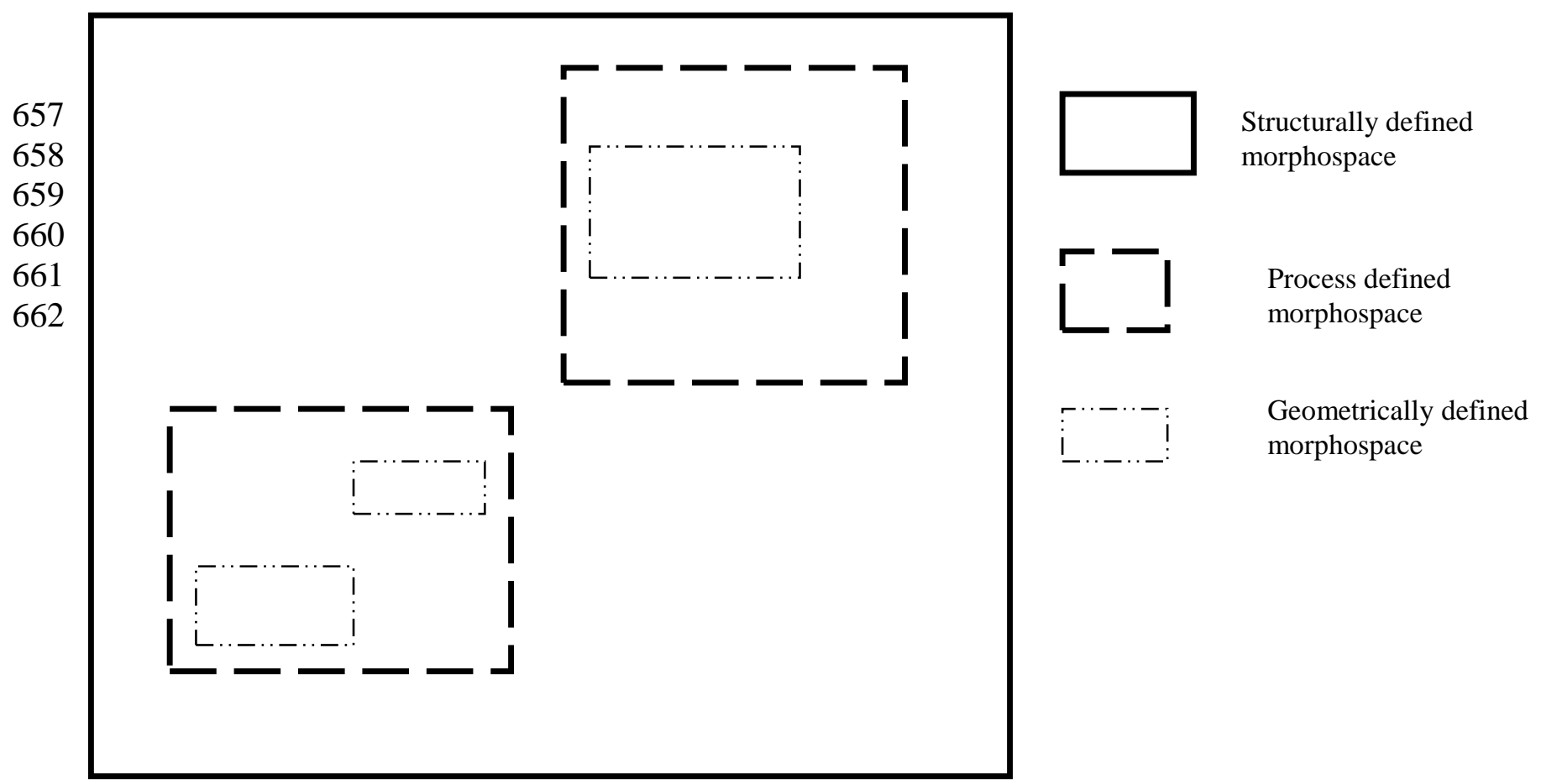




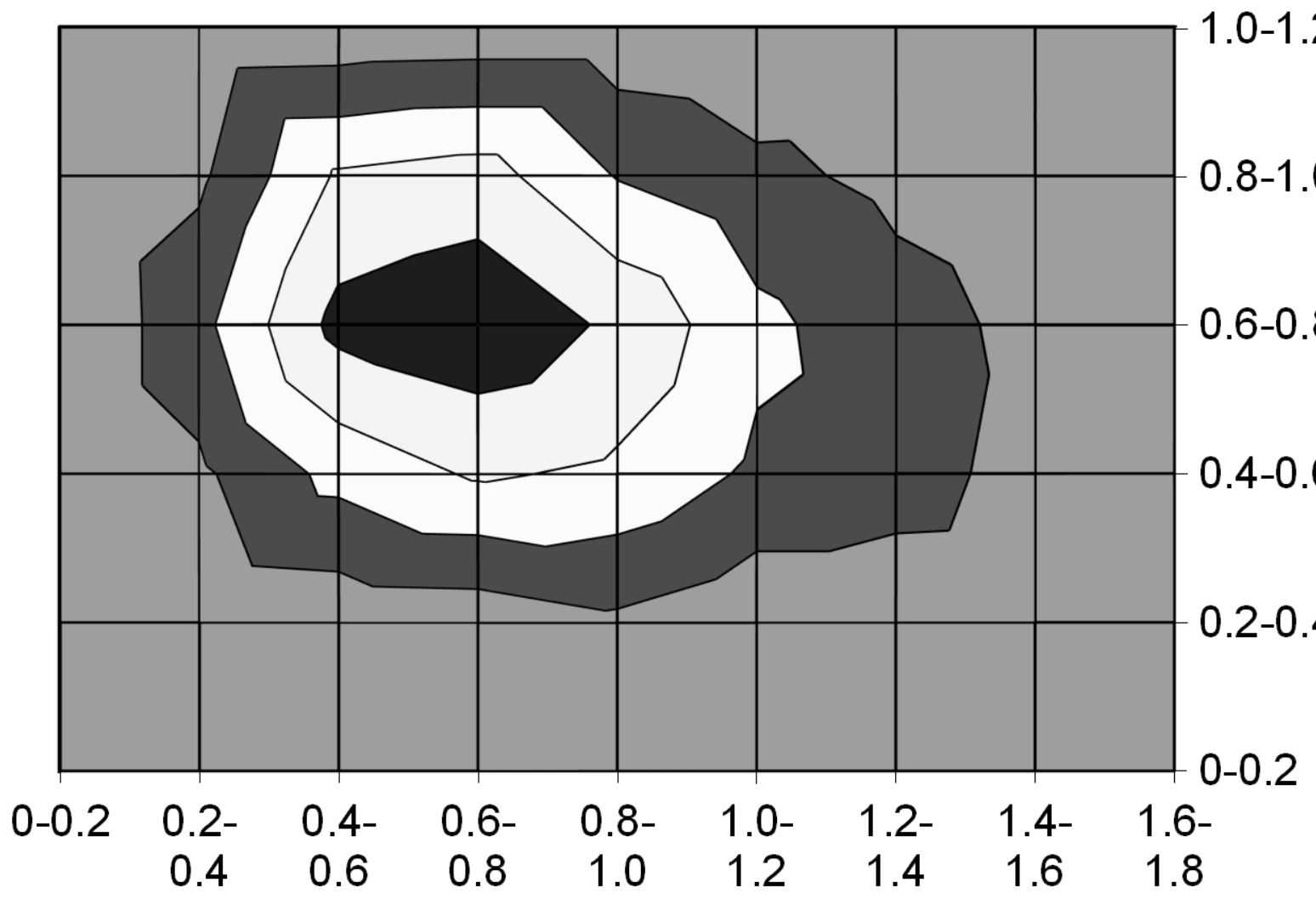


667

66: D/W

Depth high

669

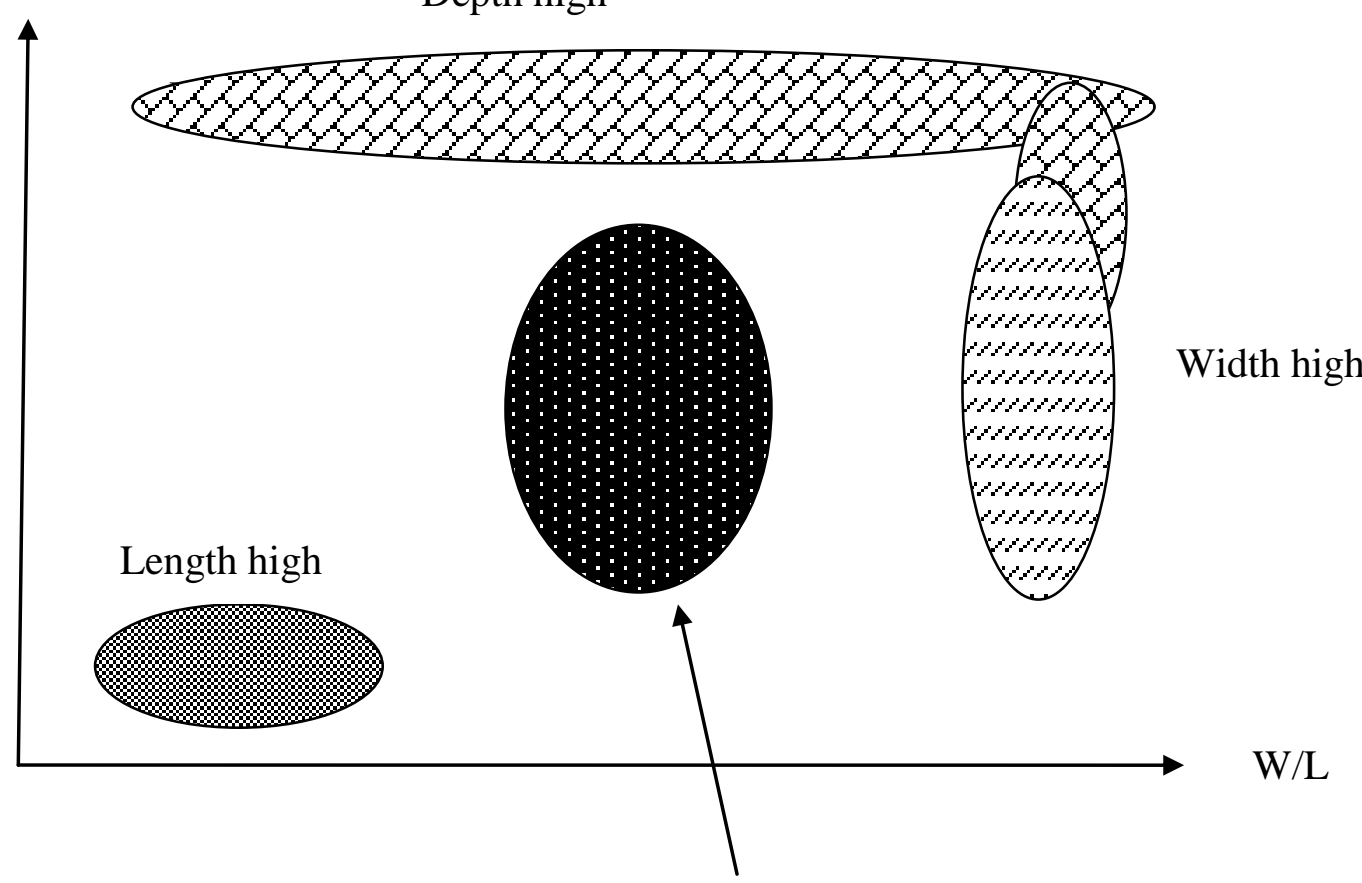

Plateau - no

significant

difference in length 
Highlights

671

- Morphospace of tafoni from Antarctica dataset defined using dimensionless

672 parameters

673

- Clustering of tafoni identified in morphospace and potential developmental

674 explanation discussed

675

- Tafoni development constrained by relational hierarchy of rock structure,

676 processes and geometry

677

678 